\title{
VIVER A SEXUALIDADE COM HIV/AIDS. DÁ PRA SER FELIZ?
}

Zenilce Vieira Bruno ${ }^{1}$; Zenilda Vieira Bruno ${ }^{2}$

\section{LIVING SEXUALITY WITH HIV/AIDS. CAN ONE BE HAPPY?}

Resumo: As DST sempre trouxeram, além da sintomatologia orgânica, um forte componente emocional. Embora hoje, a sexualidade seja vista com mais naturalidade e a conotação pejorativa das DST já não seja tão marcante, ainda é difícil falar sobre essas infecções sem constrangimento para o médico e paciente, quanto mais para o companheiro ou companheira. É necessário considerar que a liberalidade das pessoas no que diz respeito à sexualidade, é mais acentuada nos discursos do que nos atos. Parece-nos ser o componente psíquico o de maior importância nas suas repercussões sobre a sexualidade, em especial pela sensação de culpa comumente associada a essas infecções, apresenta baixa auto-estima, julga-se impuro, imoral, sujo, enfim, culpado. O prejuízo pode ocorrer em qualquer das fases da resposta sexual; é mais freqüente, entretanto, que incida na fase de desejo. $\mathrm{Na}$ atualidade, a esses fatores emocionais vem se somar à fobia generalizada do contágio com a AIDS, mais um importante elemento bloqueador do desempenho sexual.

Palavras-chave: Sexualidade; moral; culpa; desejo; desempenho.

\footnotetext{
Abstract: The STD always brought, besides the organic symptoms, a strong emotional component. Although today the sexuality is seen with more naturalness and the STD pejorative connotation is not significant as before, it still hard to talk about those infections to the doctor and to patient without been embarrassed, even more to the partner. It is necessary consider that the liberty of the people, when talking about sexuality, is bigger in the discourse

Psicóloga Clínica, Psicodramatista e Terapeuta Sexual. e-mail: zenilcebruno@uol.com.br

2 Ginecologista, Professora da Faculdade de Medicina e Diretora da Maternidade Escola da Universidade Federal do Ceará. e-mail: zenildabruno@terra.com.br
} 
than in the acts. It seems to be the psychic component of more importance in the repercussion of sexuality, especially by the sensation of guilty associated to those infections, people show low esteem, judge themselves impure, immoral, and dirty. The damage can occur in any stage of the sexual answer; frequently, however, appears in the stage of desire. Nowadays, it comes to add to those emotional factors the generalized phobia of getting AIDS, one more important element that blocks the sexual performance.

Keywords: Sexuality; moral; guilty; desire; performance.

A sexualidade humana, tão questionada nos dias atuais, faz parte de um jogo de valores transitórios e contínuos. Todo esse jogo vem, na realidade, da dificuldade que encontramos em aceitar o exercício da sexualidade fora do contexto da reprodução. Quanto a essa dificuldade de aceitação, as culturas humanas variam entre um extremo e outro, podendo-se, entretanto, classificálas genericamente em quatro grandes categorias: repressiva, restritiva, permissiva e corroboradora.

O ideal seria que houvesse uma relação de congruência entre as finalidades biológicas, sociológicas e psicológicas. Em outras palavras, que as pessoas unissem sempre harmonicamente o prazer ao amor. Mas há uma distância, às vezes, muito grande entre o ideal e o real. Mesmo porque, o próprio conceito de ideal, pressupõe toda uma roupagem antropológica e elaboração individual. O que é ideal para uma sociedade, pode não ser para a outra, o que é ideal para um, talvez não seja para o outro.

Para entender de DST e HIV/AIDS em todos os níveis da problemática humana, temos de sair um pouco da biologia da doença e caminhar pelas trilhas da psicologia da enfermidade. É necessário sair da prisão de nossas visōes tubulares, dos cubículos de nossas verdades provisórias e parciais, e tentar voar um pouco além do campo bitolado da rotina diagnóstica e terapêutica. A seara do especialista não se esgota apenas com o tratamento da doença. É preciso antes, compreender o homem dentro do fantástico mundo de sua cultura, porque só poderemos promover a saúde em seu sentido integral, quando formos suficientemente humildes, para entender que nossa verdade nem sempre é a verdade dos outros e que não é a única.

Trabalhar com o humano adoecido, não é apenas procurar a estória da enfermidade e nos esquecer de que ela se insere em uma estória de vida, de um ser que tem um passado e toda uma perspectiva, pelo menos sonhada, 
de futuro. Chegamos no tempo de repensar a ciência, que tem valorizado excessivamente a técnica e está esquecendo demasiadamente a dimensão do humano.

A profilaxia é a melhor das terapêuticas, mas no campo específico de DST e HIV/AIDS, ela é uma prática particularmente difícil. Se lida com doença que também está vinculada ao prazer sexual, e o prazer é o mais potente reforçador do comportamento humano. É ingênuo propugnar que se evitem as relações sexuais. O que se pode desejar, é que a sexualidade seja exercida sem risco, e isto, implica num processo educativo que objetive modificar atitudes. Com apreensão e desencanto, constatamos que isso não está ocorrendo com a velocidade desejada.

Talvez seja necessário lembrar aos mais novos, que o exercício da sexualidade, em especial a iniciação sexual, sofreu profundas modificações nas últimas décadas. De fato, ao contrário do que ocorre hoje entre adolescentes, a iniciação sexual masculina era realizada habitualmente com prostitutas, e o desenvolvimento de uma "doença venérea" trazia sentimentos ambivalentes. Se por um lado, isso era considerado prova de virilidade e assim causa até de jactância, em contrapartida, era também motivo para sensação de culpa, com certo ranço de "impureza".

Em épocas ainda passadas, quando os recursos terapêuticos eram muito pouco eficientes e algumas dessas doenças como a sífilis, por exemplo, pareciam praticamente incuráveis, o temor por elas desencadeado era utilizado, como ainda hoje se faz com a AIDS pelos setores mais conservadores da sociedade, visando reprimir as manifestações sexuais. $\mathrm{Na}$ estória da especialidade das Doenças Sexualmente Transmissíveis, há uma prova contundente disto. Estamos repetindo, com roupagens novas, uma história muito antiga, com as mudanças de comportamento sexual após a grande epidemia de sífilis, tanto naquela época como agora, alardearam-se medidas profiláticas e vinculou-se o medo da doença, como sendo o estímulo básico para que se modificassem práticas de risco. Durante certo tempo, o estímulo foi suficientemente forte para diminuir os comportamentos perigosos e ficou evidente uma alteração nos hábitos sexuais. Depois, passado o impacto emocional, a humanidade retornou a seus hábitos sexuais anteriores.

Embora hoje, a sexualidade seja vista com mais naturalidade e a conotação pejorativa das Doenças Sexualmente Transmissíveis já não seja tão marcante, ainda é difícil falar claramente sobre as doenças adquiridas através do sexo. Não podemos perder de vista o fato de a "educação sexual" vigente, ser ainda 
repressora em grande parte das famílias atuais, nas quais freqüentemente se associa a conotação de "pecado "à sexualidade. Isso explica por que a maioria dos portadores de HIV/AIDS ainda se sente"sujo" e "impuro", mesmo quando frente à possibilidade de baixo risco de mortalidade.

É necessário considerar que a liberalidade das pessoas, no que tange à sexualidade, é muito mais acentuada nos discursos do que nos atos propriamente ditos. Existe um padrão cultural de duplo código moral, que embora seja explicitamente monogâmico e heterossexual, implica, com certa freqüência, relacionamentos bem diferentes do que a sociedade insiste em classificar como padrão. Os movimentos sociais, entretanto, são notavelmente pendulares e sempre, na história da humanidade, períodos de liberação acentuada foram sendo substituídos por épocas mais repressoras que, após algum tempo, por sua vez, cedem lugar a novos períodos de liberação. Assim, com o passar do tempo, aquela visão extremamente liberal foi tornando-se cada vez menos radical, processo este acentuado pelo advento da AIDS, que levou a uma fase, ainda não ultrapassada, de repressão sexual.

Parece-nos ser o componente psíquico o de maior importância na repercussão referente às DST e HIV/AIDS sobre a sexualidade, em especial pela sensação de culpa comumente associada às doenças. Pacientes nos quais emerge um quadro clínico de DST e HIV/AIDS, freqüentemente apresentam notável prejuízo da auto-estima, julgando-se imorais e culpados. O prejuízo pode ocorrer em qualquer das fases da resposta sexual; é mais freqüente, entretanto, que incida na fase de desejo.

O parceiro ou parceira tem a sensação predominantemente de raiva ou de desprezo, deixando ele ou ela de ser objeto de desejo, tornando mais difícil à excitabilidade e muito longínqua a possibilidade de orgasmos. É inegável que o componente somático do ponto de vista orgânico, interfere no exercício da atividade sexual, principalmente quando desencadeia dor e desconforto, refreando os impulsos eróticos e dificultando o desempenho sexual dos parceiros. Na atualidade, a esses fatores emocionais vem se somar à fobia do contágio com a AIDS, mais um importante elemento bloqueador do desempenho sexual.

Levando em conta toda a exposição da sexualidade nos meios de comunicação voltada para adolescentes, nos perguntamos freqüentemente porque não usá-los a nosso favor, esclarecendo que esta sexualidade deve ser exercida com responsabilidade, evidenciando que este corpo tão almejado e sedutor nos levará a uma possível relação sexual e que a mesma pode nos trazer 
prazer, mas também DST e HIV/AIDS. Como se transa tanto na TV e as pessoas não contraem nenhuma doença? Será a televisão assim tão mágica? Se tivéssemos propagandas tão competentes quanto as que vendem artigos de beleza, em que os adolescentes acreditassem que usando camisinha seriam tão belos e felizes quanto aqueles modelos e manequins das revistas e outdoors, não evitaríamos assim, esta quantidade de tantos casos novos de AIDS a cada ano?

Não desejamos reduzir os meios de comunicação a meros estimuladores do consumo ou de práticas sexuais, pelo contrário, julgamos terem eles importantíssimo papel na sociedade moderna, papel este que, infelizmente, não vem sendo cumprido a contento. Sabemos que a TV e os outros tipos de mídia se transformaram na principal fonte de educação sexual, mostrando um conteúdo cada vez mais sexualmente explícito, com pouquíssimas referências as DST e HIV/AIDS. Alguns têm apenas começado a quebrar esta "conspiração de silêncio", trazendo informações úteis e reais aos adolescentes. Como esse paradoxo ocorreu? Aumentam o conteúdo sobre sexo e violência e se calam sobre DST e AIDS.

Pergunta-se com freqüência se, nestes tempos da AIDS, os costumes e os hábitos sexuais foram modificados. Em termos gerais e num primeiro momento, sim, no entanto, os hábitos e os costumes voltaram ou estão voltando à trilha antiga, portanto somos forçados a admitir que a doença não está sendo controlada. A informação correta é essencial, mas ela só é válida, quando é capaz de mobilizar o componente afetivo da personalidade e levar a refletir, reformular conceitos, propósitos e condutas. A maioria sabe que a melhor maneira de prevenir as doenças que se transmitem por via sexual, é evitando as condutas de risco e utilizar profilaticamente o condom. Sabem, mas não utilizam.

Propomos uma reflexão, sair do espaço limitado de nossas especialidades e, com humildade, ouvir, e, sobretudo tentar valorizar o intercâmbio entre os profissionais de saúde e educação e os adolescentes, assim como, com seus pares e familiares. Ampliando a visão do homem e sua relação com o ambiente, tratando sempre a doença e o doente com a mesma importância.

O tratamento realizado não pode ser muito lento, pois algumas vezes as inadequações sexuais corroem de tal forma o relacionamento, que muitos desistem da terapia e do casamento. É necessário agilizar o processo, através de uma terapia breve que seja suficientemente eficaz para restaurar os laços entre os pares, antes que eles se desfaçam por completo. 


\section{Bibliografia Consultada}

ABDO, C.H.N. Sexualidade humana e seus transtornos. São Paulo: Lemos Editorial, 2000.

BASTOS, A.C. Ginecologia. 10 ed. São Paulo: Guanabara-Koogan, 1998. BRAGANTE, L. Amor e sexualidade: a resolução dos preconceitos. $2^{a}$ ed., São Paulo: Gente, 1994.

BRASIL, Ministério da Saúde. Programa Nacional de Doenças Sexualmente Transmissíveis/AIDS - Boletim Epidemiológico. Brasília, Ano IX, n. 6, março de 1997.

CARIDADE, A. Sexualidade: Corpo e metáfora. São Paulo, Iglu: 1997. CAVALCANTI, R. Saúde sexual e reprodutiva. Editora Artgraf, s/d.

COSTA, M. Amor e sexualidade. São Paulo: Editora Gente, 1994.

DIAS, V.R.C.S. Vínculo conjugal na análise psicodramática: diagnóstico estrutural dos casamentos. São Paulo: Agora, 2000.

FOUCALT, M. História da sexualidade. vol I. Rio de Janeiro: Editora Graal, 1998.

KAPLAN, H.S. A nova terapia do sexo: tratamento dinâmico das disfunçōes sexuais. Rio de Janeiro: Nova Fronteira, 1977.

MASTERS, W.H.; JOHNSON, V.E.; KOOLODNY, R. O relacionamento amoroso. Rio de Janeiro: Editora Nova Fronteira, 1985.

MURARO, R. M.; BOFF, L. Feminino e masculino. Uma nova consciência para os encontros das diferenças. Rio de Janeiro: Sextante, 2002.

PASSOS, M.R.L. Deessetologia. In: PASSOS, M.R.L. DST 5. - $5^{\mathrm{a}}$ ed. Rio de Janeiro: Cultura Médica, 2005.

VITIELLO, N. Educação sexual. Reprodução e sexualidade: um manual para educadores. São Paulo: CEICH, 1994.

ZAMPIERI, A.M.F. Erotismo, sexualidade, casamento e infidelidade: sexualidade conjugal e prevenção do HIV e da AIDS. São Paulo: Ágora, 2004. 